Article

\title{
Connecting Environmental Humanities: Developing Interdisciplinary Collaborative Method
}

\author{
Gavin Little 1,2,3 \\ 1 Professor of Environmental and Public Law, Stirling Law School, University of Stirling, Stirling FK9 4LA, \\ UK; g.f.m.little@stir.ac.uk \\ 2 Principal Investigator of the Royal Society of Edinburgh funded Research Network in the Arts and \\ Humanities Connecting with a low-carbon Scotland, Centre for Environment, Heritage and Policy, \\ University of Stirling, Stirling FK9 4LA, UK \\ 3 Adjunct Professor, School of Law, Queensland University of Technology, Brisbane QLD 4001, Australia
}

Received: 31 August 2017; Accepted: 11 November 2017; Published: 15 November 2017

\begin{abstract}
There is now a consensus that the potential contribution of the humanities to wider environmental debate is significant, although how to develop it effectively is still unclear. This paper therefore focusses on realizing the potential of the environmental humanities through building interdisciplinary collaboration. A four-stage research model is outlined for areas where there is limited humanities scholarship, based on ongoing experience of the humanities in action in the Royal Society of Edinburgh Research Network in the Arts and Humanities, Connecting with a low-carbon Scotland. The model has two key objectives: (1) to enable humanities disciplines to articulate their own contributions to pre-identified environmental research issues; and (2) to develop interdisciplinary humanities collaboration on these issues. It can be adapted to develop understanding in local, national and international contexts, depending on the number of scholars involved and the available resources. The knowledge which emerges can facilitate further interdisciplinary working between the humanities, STEM subjects and social sciences, and be of value to environmental policy-makers.
\end{abstract}

Keywords: environment; humanities; interdisciplinary; collaboration; method; policy; low-carbon; model; narrative; network

\section{Introduction}

In recent years, there has been rapid development of the broad field of environmental humanities. There has also been a growing understanding in the STEM ${ }^{1}$ subjects and quantitative social sciences, which until now have dominated environmental scholarship, that the humanities have a significant contribution to make. For while STEM and social science disciplines can develop understanding of the natural environment, new technologies and social policy, confronting issues such as climate change, sustainability or moving to a low-carbon future requires massive cultural shifts. In consequence, there is a pressing need for the humanities to bring together and explore important cultural influences and factors in order for science, social science, policy-makers and society to understand and address them better and more effectively (Rose et al. 2012; Sörlin 2012, 2013; Griffiths 2007; Palsson et al. 2013; Holm et al. 2013; Little 2016a, pp. 64-69).

But working out how the environmental humanities can best make this contribution is not always straightforward (Holm et al. 2015, pp. 985-87). The environmental humanities is a generic term encompassing research in a diverse range of disciplines. It includes, among others, visual arts, literature and theatre, history, philosophy, politics, law and media studies. Each of these disciplines has

1 i.e., science, technology, engineering and mathematics. 
its own sub-specialisms, (sometimes conflicting) theoretical perspectives, substantive knowledge bases and approaches: there are no unifying methods and it is fair to say that in most there is an absence of a developed culture of collaborative team working. In contrast, and notwithstanding that one should be careful not to think of them as a monolithic or collective entity, the environmental sciences and social sciences do share core quantitative methods and researchers in them are often more accustomed to working in collaborative teams.

With this in mind, it is argued that by joining together in collaborative partnerships, environmental humanities scholars can not only drive forward their own disciplines, but also develop new inter-humanities understandings which can facilitate wider interdisciplinary research and assist policy-makers (n.b. the term 'inter-humanities' is used here to mean interdisciplinarity within the humanities). After short contextual discussions of key issues in the environmental humanities and then interdisciplinarity, the paper addresses the special edition theme of 'the environmental humanities in action' by drawing on the experience of the Royal Society of Edinburgh funded Research Network in the Arts and Humanities Connecting with a low-carbon Scotland ('the RSE network') ${ }^{2}$ and the Stirling Centre for Environment, Heritage and Policy ('the SCEHP') ${ }^{3}$ to suggest a four-stage model for collaborative interdisciplinary working in areas where humanities scholarship is still relatively undeveloped. This has the twin objectives of (1) enabling individual disciplines to articulate and plan the contributions that they can make to pre-identified research issues; and (2) creating inter-humanities collaboration on these issues. The knowledge which emerges can then provide a platform for further interdisciplinary working with STEM subjects and quantitative and qualitative social sciences, and be of value to policymakers and society. The method can also be adapted to develop understanding in local, national and international contexts, depending on the issues, the number of scholars involved and the resources available. Consideration is then given to some wider implications for interdisciplinary collaboration and the environmental humanities which are emerging from the RSE project. Finally, a brief conclusion summarises the main argument.

\section{Key Conceptual Issues in Environmental Humanities Scholarship}

The last fifteen years has seen the development of an impressive corpus of environmental humanities research (Heise 2014; 2017, pp. 1-2). It is comprised of articles in mainly discipline-centric journals, monographs and, increasingly, edited collections with contributions from authors in different disciplines. The high quality of much of it has gone a considerable way to establishing environmental scholarship within the humanities in a relatively short period of time. And, without doubt, the growing use of the term 'environmental humanities', implying as it does the sense of an established academic community and intellectual kinship, is much more than a reaction to the still recent marginalisation of the environment within some disciplinary mainstreams (for example, (Fisher et al. 2009, pp. 221-23; Little 2016a, pp. 55-60)). It expresses a determination to be proactive and to engage meaningfully with others across subject boundaries, certainly within the humanities and, potentially, between the humanities and the sciences, social sciences and policy-making.

That said, however, and while some works which were written in and for specific disciplines have come to have wider significance (Heise 2017, pp.1-2), care perhaps needs to be taken to not overstate the extent of interdisciplinary connection in the environmental humanities. Currently, and notwithstanding the rapid and recent growth of a number of humanities projects and initiatives across the world (Holm et al. 2015, pp. 987-89), collaborative interdisciplinary working is still relatively new. Much of the existing scholarship is not easily accessible to those who are not experts in particular disciplines, and it may have limited relevance for wider readerships. This is not a criticism, as the main objective

2 Royal Society of Edinburgh Research Network in the Arts and Humanities Connecting with a Low-Carbon Scotland website, available at: https:/ / www.stir.ac.uk/cehp/projects/connectingwithalow-carbonscotland/ (accessed on 30 October 2017).

3 Stirling Centre for Environment, Heritage and Policy website, available at: https:/ /www.stir.ac.uk/ cehp/ (accessed on 30 October 2017). 
of much humanities research, as with much science and social science research, is to contribute to discipline-centric specialisms (although, as already noted and expanded on below, humanists are often sole-authors, while scientists are more accustomed to team working). Thus, for example, literary studies analysing novels themed around the effects of climate change on indigenous peoples or landscapes may not have - and, reasonably and rightly, may not be intended to have-wider resonance beyond a relatively small community of eco-critics. So, to be clear, it is not being suggested that environmental humanists should not be engaged in producing solo scholarship which deepens understanding within their specialisms: doing so is at the core of the academy and will doubtless continue to be so. Rather, it is contended that developing the field means not only pursuing discipline-centric, specialist research, but also building new interdisciplinary collaborations (Little 2016a, pp. 60-61, 64-73; Holm et al. 2015, p. 986; Hamilton et al. 2009). Moreover, the former may benefit from the insights which emerge from the latter and vice versa: a multi-track approach can be synergistic (Little 2016a, pp. 73-74).

Realising this ambition, however, leads to a key question that has to be addressed at the outset. For if environmental humanities research is often conducted by lone scholars pursuing a range of diverse and specialist disciplinary approaches and schemas, what are the factors which connect it?

One way of answering the question is to stand back and think about the environmental humanities as a broad church: doing so clarifies common themes which can then be built on to develop more structured interdisciplinary collaboration. Notwithstanding the range of theoretical complexities in the scholarship, or its discipline-centric content and sometimes culture-specific nature, it is argued that four key issues emerge from this process. These provide the conceptual context to the RSE network and influenced the design of its four-stage model.

Firstly, at the meta-level, environmental humanities research can, of course, be said to be concerned with developing understanding of ecological events as cultural phenomena, rather than as solely scientific or technological ones. It is therefore often concerned with different aspects of justice, fairness and equality, and with contested histories and philosophical values (see for example (Adamson and Davis 2017; Sörlin and Warde 2009; Gardiner and Thompson 2015; Isenberg 2014; Garrard 2014; Heise et al. 2017; Smout 2009; Plumwood 2001)). These have sometimes been contextualised within the over-arching theme of the Anthropocene-the idea that human activity is now so powerful that it is having a major (and potentially catastrophic) effect on the Earth's ecology, and that humans are such that they have the insight to perceive their impact within nature (Jamieson 2017; Steffen et al. 2011; Palsson et al. 2013; Heise 2014, pp. 20-24).

The Anthropocene provides the intellectual backdrop to diverse re-evaluations of ideas of time, narrative and history. These have explored a wide variety of ecologies in fictional, non-fictional and visual narratives (see for example (Adamson and Davis 2017; Sörlin and Warde 2009; Smout 2009; Gardiner and Thompson 2015; Isenberg 2014; Garrard 2014; Heise et al. 2017)). The significance of different approaches in the development of environmental politics and law has also been assessed (for example, Gabrielson et al. 2016; Fisher et al. 2013). In addition, the Anthropocene, involving as it does vast timescales and global consequences, has led humanists to re-evaluate core ideas such as gender, race, class, inter-generational relations and nationalism (Chakrabarty 2009; Heise 2014, pp. 22-23). And, inevitably, the Anthropocene raises profound ethical and philosophical questions about situating humanity and its agency in nature and time (Jamieson 2017; Martell 1994, p. 77). In this context, the post-humanist ideas of writers such as Bruno Latour have been influential (Latour 1991). So too is the distinction between anthropocentric approaches (i.e., those which focus on and prioritise human interests within the context of an ecologically sustainable society) and ecocentric ones (i.e., those which, in addition to this, posit a broader idea of human development which recognises the moral value of the non-human world and its development) (Eckersley 1992, p. 26).

In short, environmental issues are inseparable from the tangled skein of human perceptions. Humanities scholars therefore have a major part to play in exploring these perceptions and deepening understanding of them, along with social scientists such as anthropologists and economists. So, the primary focus of the environmental humanities is, taken together, on the cultural and intellectual 
interactions between humans and what we conceptualise as 'the environment': the core objective is that of contributing to the interpretation and judging of human perception on, and knowledge of, environmental issues. Hence, for example, while the STEM subjects are concerned with studying climate change caused by fossil fuel use and creating low carbon technologies to mitigate it, the humanities can, along with qualitative social sciences, provide different insights into how these phenomena are perceived in cultural terms, thereby making a valuable contribution to the meta-debate on how society might approach them.

In this context, the environmental humanities can also help bridge the intellectual gaps between scientific timescales, which in the case of climate change can play out over thousands of years, and more easily comprehensible timescales such as a human lifespan (McNeill 2001, chp. 1; Griffiths 2007, p. 4; Roberts 2014). By engaging with defined, accessible timescales and focusing on subjects such as specific landscapes or cultures, humanists can provide valuable perspectives on the interactions between people and their environments (see for example (Clapp 1994; Simmonds 2001; Sheail 2002; Smout 2009; Warde 2008; Roberts 2014, chp. 1)). They can also provide important critiques by setting science and its methods in broader human and social contexts, with the objective of influencing and improving the ways in which scientists and policymakers interact and communicate with the public (Griffiths 2007, pp. 4-5; Little 2016a, pp. 68-69, 70-73).

Secondly, and despite their wide diversity in terms of subject matter, theory and method, the environmental humanities are also connected by their focus on analysing different forms of narrative, or story: it is the centrality of narrative and its critique which has perhaps the greatest potential to bring the environmental humanities together as a body of scholarship. To point to the significance of narrative in the humanities is, of course, anything but original (see for example (Griffiths 2007, p. 4; Shaw 2013; Cover 1983; Little 2016a, pp. 67-68; Heise 2017, pp. 6-9; Holm et al. 2015, p. 981)). Its importance in shaping our ideas on what has happened, is happening and may happen, and in influencing the future is well understood. Narratives-whether fictional, non-fictional, theatrical, visual, oral, musical, sculptural, historical, contemporary, digital, realist, abstract, on the page or on the screen-have powerful and sophisticated effects on the way that we think, feel and behave, as individuals and as societies. The humanities therefore utilise a range of different narrative critique-based methods to interconnect and analyse complex issues: in this respect, the humanities differ from scientific methods which often tend to test and analyse their subjects on an individual basis (Griffiths 2007, p. 4). So, by focussing on the critique of culturally powerful narratives, the humanities can facilitate the development of a better understanding of how people access and are influenced by the mixture of truths, misconceptions and issues which are embedded in them—sometimes explicitly and sometimes not.

Thirdly, all of the humanities are united in having to grapple with environmental issues which are themselves difficult, controversial, interconnected and multidimensional (Dryzek 2005, pp. 8-9). There is the interweaving of the biophysical ecosystem, incomplete scientific knowledge, and the social, political, economic, cultural and legal aspects of humanity to contend with. In addition, major issues such as climate change and low carbon transition require action at global, local and individual levels if they are to be tackled successfully (Fisher et al. 2013, pp. 23-31). Taken together, environmental issues are classic examples of the legal philosopher Lon Fuller's polycentric (or 'many-centred') problems: each crossing of the different strands which link them together is a 'distinct centre for distributing tensions', as if in a spider's web, making it extremely difficult to understand how best to approach them (Fuller 1978, p. 395).

Moreover, disagreement over how to approach key environmental issues is, given the degree of scientific uncertainty, often centred on what is understood as fact (Latour 1991, p. 1). The positions which are adopted by individuals and societies are, to a considerable extent, reflections of the importance of, and differences over, competing values. Indeed, as the continuing controversy over whether climate change is happening and, if it is, whether it has been caused by human activity demonstrates that environmental knowledge is mixed together with ethical and socio-cultural values. 
These values 'fill gaps left by uncertainties' (Fisher et al. 2013, p. 45) -even when, as is the case with climate change, the overwhelming scientific consensus is clear. This dynamic impacts on the directions taken by science, public opinion, policy-making, law and government: environmental humanists therefore recognise, among other things, that critical evaluation of environmental issues is often perceived and experienced culturally via a subjective rather than an objective process (Fisher et al. 2013, ibid).

Now, of course, scientists, social scientists and policy-makers have to confront these issues too, albeit in different ways. But the complexity of humanity's interaction with its environment is exactly the sort of intellectual context in which the humanities flourish: indeed, as already suggested, developing understanding of the diverse and multi-layered complexity of cultural influences and their effects is what they are about, what makes them distinctive intellectually and what unites them across disciplinary boundaries.

Fourthly, the humanities are, it is argued, brought together by the need to acknowledge that they are sometimes relative newcomers to environmental debates. Not unreasonably, humanities scholarship-although growing rapidly-is not always at the same stage of maturity as those sciences and quantitative social sciences which have dominated the environmental field, in some cases for decades. While saying this may seem self-critical, it would, it is contended, be unrealistic not to recognise it as a real issue, particularly given that many in the sciences, social sciences and policy-making still struggle to see the relevance of interaction with the humanities. In consequence, when approaching environmental issues where humanities scholarship is still relatively undeveloped by comparison with relevant sciences and social sciences, humanists may need to step back into their own disciplines, and consider what their primary expertise can bring to the table with clear eyes, almost as if from first principles (see for example (Little 2016a, pp. 54-61; Fisher et al. 2009)). Admittedly, reflective practice is not always a comfortable process-indeed, it is sometimes salutary. But, given the still nascent stage of the humanities in some environmental areas, it may be an important one if we are to minimise the risks of failing to maximise potential or of producing flawed research.

\section{Interdisciplinarity: Key Definitions and Issues}

Against this broad conceptual backdrop, initiatives such as the Humanities for the Environment Observatories ("HftEOs") ${ }^{4}$, The Seed Box ${ }^{5}$, the UK research councils' Global Research Challenges Fund $^{6}$ and, on a smaller Scottish scale, the SCEHP and the RSE network are all seeking to facilitate interdisciplinarity: one of the most exciting aspects of these and similar projects is the potential that they have to explore collaborative inter-humanities approaches to particular issues, which can then be used in broader interdisciplinary collaboration with the sciences, social sciences and policymaking. In a UK context, following support for interdisciplinarity in Lord Stern's influential report on the Research Excellence Framework ("REF”) ${ }^{7}$ (Stern 2016, para. 39-42), and increased funding from the main research councils 8 , academics are now engaging with it in greater numbers. There have been similar developments elsewhere (Derry et al. 2013, pp. xiv-xvi; Holm et al. 2013, pp. 30-35). Before expanding on the RSE project and model, however, we should give brief consideration to defining interdisciplinarity-for the terminology is often used inconsistently, and we need to be careful about what is meant by it.

\footnotetext{
See the Humanities for the Environment website at: http:/ / hfe-observatories.org (accessed on 30 October 2017). See the Seed Box website at: http:/ / theseedbox.se (accessed on 30 October 2017).

See the Research Councils UK Global Challenges fund website at: http:/ / www.rcuk.ac.uk/funding/gcrf/ (accessed on 30 October 2017).

The REF is the UK-wide system for assessing research quality in higher education institutions.

8 For example, see the explicitly interdisciplinary themes of the UK Arts and Humanities Research Council at http://www. ahrc.ac.uk/research/funded themesandprogrammes/themes/ (accessed on 30 October 2017).
} 
A widely accepted definition of interdisciplinary working is that it is a method of conducting research that 'integrates, among other things, techniques, perspectives, concepts and/or theories from more than one discipline to develop knowledge in a way that would be beyond the capacity of a single discipline' (Little 2016a, p. 61; National Academy of Sciences et al. 2005, p. 2; Klein 1996; Vick 2004, pp. 164-65, 181-91). This can be done, as in many humanities disciplines, by a lone scholar drawing from more than one discipline (Little 2016a, p. 63), but the main focus of most discussions of interdisciplinarity (which are concerned predominantly with science and social science) is collaborative group working. Central to it is the ideal of engaging experts from a range of disciplines in challenging dialogues which are transformational for their understanding, and which lead to the creation of new knowledge, perspectives, answers and even disciplines (Derry et al. 2013, p. xii).

Other terms which are used widely are multidisciplinary, crossdisciplinary and transdisciplinary research. Broadly, the first seeks to draw from a range of separate disciplines, but not to integrate them (Little 2016a, p. 62; European Science Foundation and European Cooperation in Science and Technology 2012, p. 48). Here, disciplinary identities are maintained, and the objective is to use a limited number of shared or borrowed concepts across subject boundaries. Some argue that this sort of process has in fact been more effective than interdisciplinarity in leading to major breakthroughs (Rogers et al. 2013). Crossdisciplinarity is usually used to refer to the process of collaboration across disciplines to solve complex problems. It tends to stress the importance of effective management, leadership and communication (Pennington 2008). Transdisciplinary research is similar to interdisciplinarity in that it seeks to develop new approaches and ways of thinking about complex issues that transcend disciplinary identities (Klein 2008, Sect. 117; Little 2016a, ibid.; Bruce et al. 2004). Although the term is often used loosely (and is inter-related with concepts such as 'post-normal science' (Funtowicz and Ravetz 1991)), it has been defined as research which seeks to produce new ideas from in-depth participation between academics and practitioners in the context of real-world problems (Polk 2014): the involvement of non-academic experts distinguishes transdisciplinarity from interdisciplinarity (Padmanabhan 2017).

A further distinction which is returned to in the discussion of the RSE network model is that of radical and moderate interdisciplinarity (Holm et al. 2013, pp. 28-29). The radical variant involves scholars working across major disciplinary boundaries-such as theatre and environmental science-while the moderate one takes place between scholars in intellectually cognate disciplines such as law and policy, philosophy and religious studies, politics and history, or visual arts and media (European Science Foundation and European Cooperation in Science and Technology 2012, p. 48; Little 2016a, ibid.). And, of course, any discussion of interdisciplinarity needs to recognise that disciplinary identities themselves are at the same time enduring, resilient, self-sustaining, fuzzy, contested, sub-divided and constantly evolving (Vick 2004, pp. 166-70).

Liz Fisher, a leading environmental law scholar, has argued that interdisciplinary scholarship 'requires the ongoing fostering of a specific type of expertise' (Fisher 2016, pp. 2-4). She draws on an additional and insightful distinction made by Collins and Evans-that is, between ideal types of 'interactional' and 'contributory' expertise. The former is a level of expertise which enables participants in an interdisciplinary project to be able to 'interact interestingly with' those from other disciplines and to engage in sociological analysis. The latter, however, is where participants have sufficient expertise to actually 'contribute to the science of the field being analysed' (Collins and Evans 2002, p. 254). The existence of interactional expertise enables participants from different disciplinary backgrounds to talk about issues in a common 'practice language' (Collins and Evans 2015, p. 119). Among other things, it is therefore essential that it is planned and managed effectively: otherwise, it runs the risk of producing outcomes which are flawed-or even perverse and dangerous (Collins and Evans 2015, pp. 121-22). Contributory expertise may be characterised as being inherently more challenging, as it requires a great deal of effort on the part of participants to learn about new disciplines, in order that they are able to make significant contributions across disciplinary boundaries. 
It is axiomatic that moderate interdisciplinarity tends to imply a high degree of interactional expertise, which becomes progressively more difficult to sustain as the relationship between disciplines involved becomes more radical. It is also the case, arguably at least, that the greater the degree of interactional expertise, the more fruitful the interdisciplinary collaboration may be and the greater the likelihood of contributory expertise developing - provided the process is well designed and channelled effectively.

To conclude this section, and in a spirit of realism, the potential downsides of interdisciplinary working should also be acknowledged, as they are significant. The first is self-evident. Much time, effort and resource can be expended on interacting with scholars working in other disciplines, but little of academic value may emerge. Interdisciplinary collaboration can, as a method, be ineffective and wasteful and the output may be academically weak, particularly if scholars do not recognise that they lack expertise in areas other than their own or they have developed a working method which turns out to be flawed. In short, it is a high risk venture. To avoid this, interdisciplinary research groups need to be able to arrive at clear objectives and methods which have been thought through and agreed at the outset by all involved, a point that will be returned to in the discussion of the RSE network model.

The second pitfall is that many institutions, for all that they may now appear to be championing collaborative interdisciplinarity, are in reality structured in such a way as to put up barriers against it (National Academy of Sciences et al. 2005, pp. 88-93; EURAB 2004, pp. 2-3, 5-6, 10). Most humanists work in conventional university departments which are specialist disciplinary silos. This is not unreasonable, because scholars must develop primary expertise in their subject area: the organisational rationale has therefore been to focus resources on developing specialism rather than interdisciplinary working. And in the UK context, this dynamic has arguably been reinforced over the past twenty years by successive REFs, which have been based around subject specialist units of assessment (Stern 2016, para. 39-42). ${ }^{9}$ So, it can still be difficult for scholars (and their universities) to break out of often very established organisational structures and ways of thinking, and to establish meaningful and effective connections with those in different disciplines. To do so requires time and for individual scholars to be proactive, bold and phlegmatic about rejection, both by prospective partners in other disciplines and by those in their own discipline who focus on more orthodox approaches to research. And for universities and funders to be serious about making a success of interdisciplinary collaboration, they need to provide more than warm words, and reform their institutional objectives, resourcing, structures and processes (National Academy of Sciences et al. 2005, chp. 5).

Moreover, the risks for individual scholars who choose to collaborate across disciplines are potentially considerable. As noted earlier, interdisciplinary collaboration runs contrary to the humanities tradition of the lone scholar and it is also very time-consuming. Certainly, in the pre-Stern REF environment in the UK, it is reasonable to think that collaborative researchers may have been disadvantaged by comparison with sole authors who are able to publish more. Collaboration-based outputs may also be co-authored rather than sole-authored, which has had the potential, whether fairly or unfairly, to lessen their perceived worth in REF terms within institutions, particularly in the humanities. And it is not always clear how interdisciplinary outputs will be assessed in university-level "mock" REFs, or the real thing (Stern 2016, para. 39-42). It remains to be seen whether these aspects of the research environment will change in the UK as a result of Stern.

In addition, journals are for the most part also silo-based, specialist publications. This means there can be particular difficulties in getting interdisciplinary research published-editors and referees may be more likely to be cautious about accepting interdisciplinary articles. Not only are they difficult to assess, but the main readership may be more interested in established debates. And, notwithstanding the recent increases in funding for interdisciplinarity, it is still reasonable to think that it may be very difficult to obtain financial support for it: funders might find it harder to assess interdisciplinary 
proposals (which are also more difficult to construct) and there will be increasing competition for resources as more scholars apply.

In sum, therefore, it might be that academics pursuing interdisciplinary research could find that they have made their professional lives harder than they would otherwise have been. Indeed, in their 2004 report, the US National Academies made the point that university structures and criteria for career development can make it more difficult for interdisciplinary researchers to be appointed, get tenure and be promoted (National Academy of Sciences et al. 2005, pp. 69-79). While the situation is now much more supportive, it is still reasonable to think that developing a profile in collaborative interdisciplinary research could impact adversely on career prospects.

\section{The Environmental Humanities in Action: Creating a Model for Interdisciplinary Collaboration}

In Scotland, pioneering work on interdisciplinary collaboration within the environmental humanities has been based at the SCEHP, which provided the essential environment and support for its instigation and development (Hamilton et al. 2009). The RSE network, which is also hosted at the SCEHP, has built on this foundation and on ecological scholarship on an interdisciplinary method (e.g., Turner and Carpenter 1991; Frost and Jean 2003; Bruce et al. 2004; Amey and Brown 2005; Boulton et al. 2005; Benda et al. 2002). While it is still a work in progress, the basic design of its research model is straightforward and transferable to other situations where environmental humanities perspectives are relatively undeveloped: it has the potential to be scaled up or down, depending on the issues under consideration. The model has four interlinked stages, which are discussed below along with its potential biases after a short background summary of the RSE project. Table 1 also sets out the key features of the model.

Table 1. A Four Stage Model for Interdisciplinary Collaboration in the Humanities

\begin{tabular}{|c|c|c|}
\hline $\begin{array}{l}\text { Table 1: A Four Stage Model for } \\
\text { Interdisciplinary Collaboration } \\
\text { in the Humanities }\end{array}$ & Key Tasks/Considerations & Outcomes \\
\hline Stage 1: Network Formation & $\begin{array}{l}\text { 1. Formation of core interdisciplinary } \\
\text { humanities group; } \\
\text { 2. initial identification of themes and } \\
\text { objectives for collaboration; } \\
\text { 3. proactive recruitment from humanities } \\
\text { disciplines; and } \\
\text { 4. minimum physical meetings and maximum } \\
\text { use of IT. }\end{array}$ & $\begin{array}{l}\text { 1. Large network of interested humanities } \\
\text { scholars linked mainly by IT; and } \\
\text { 2. Clear themes and objectives for future } \\
\text { collaboration established. }\end{array}$ \\
\hline $\begin{array}{l}\text { Stage 2: Project Development } \\
\text { (e.g., in context of grant } \\
\text { application) }\end{array}$ & $\begin{array}{l}\text { 1. } \begin{array}{l}\text { Engage with STEM/social } \\
\text { science/policy-making experts to inform } \\
\text { project development; } \\
\text { possible use of scenarios to } \\
\text { develop/structure project; }\end{array} \\
\text { 3. } \begin{array}{l}\text { open, collaborative and } \\
\text { collegiate communication; }\end{array} \\
\text { equal time and opportunity for participants } \\
\text { to contribute; } \\
\text { maximum use of IT and minimum } \\
\text { physical meetings; } \\
\text { 6. } \begin{array}{l}\text { plenary meeting to finalise project design, } \\
\text { set milestones, agree methods, allocate } \\
\text { responsibilities, etc.; and } \\
\text { subsequent written summary report by } \\
\text { network lead to be adopted by consensus. }\end{array}\end{array}$ & $\begin{array}{l}\text { 1. Early incorporation of STEM/social science, } \\
\text { policy-making expertise in project design; } \\
\text { 2. Written report setting out agreed project } \\
\text { objectives etc./grant application. }\end{array}$ \\
\hline
\end{tabular}


Table 1. Cont

\begin{tabular}{|c|c|c|}
\hline $\begin{array}{l}\text { Table 1: A Four Stage Model for } \\
\text { Interdisciplinary Collaboration } \\
\text { in the Humanities }\end{array}$ & Key Tasks/Considerations & Outcomes \\
\hline $\begin{array}{l}\text { Stage 3: Disciplinary } \\
\text { Humanities Panels }\end{array}$ & $\begin{array}{l}\text { 1. Identify discipline panels, panel chairs and } \\
\text { panel members (maximum } 8 \text { per panel, incl. } \\
\text { 1 Ph.D. student); } \\
\text { 2. } 6 \text { weeks before each panel, selected } \\
\text { narratives chosen by panelists circulated to } \\
\text { panel by Dropbox; } \\
\text { one-day panel meetings, chaired and } \\
\text { recorded, with structured discussion of } \\
\text { narratives and pre-agreed themes/issues } \\
\text { (use Skype/telecon if physical meeting } \\
\text { difficult); } \\
\text { panel reports drafted jointly by network } \\
\text { lead and panel chairs, then circulated to } \\
\text { panel members; and } \\
\text { finalised panel reports circulated to all } \\
\text { network participants. }\end{array}$ & $\begin{array}{l}\text { Formal, written panel reports, produced by } \\
\text { a range of humanities disciplines, } \\
\text { identifying and exploring disciplinary } \\
\text { perspectives on the project topic. }\end{array}$ \\
\hline Stage 4: Inter-Humanities Report & $\begin{array}{l}\text { 1. Network lead and panel chairs draft } \\
\text { inter-humanities report, drawing on and } \\
\text { blending the panel reports; } \\
\text { draft report circulated to network and } \\
\text { revised via online iterative process on } \\
\text { Dropbox, moderated by network lead; } \\
\text { 3. } \begin{array}{l}\text { second draft prepared by network lead and } \\
\text { panel chairs, then circulated for final } \\
\text { comment and review; } \\
\text { network lead finalises report (for online } \\
\text { publication/incorporation into research } \\
\text { project report, etc.); }\end{array} \\
\text { proactive development of wider } \\
\text { interdisciplinary impact in } \\
\text { policy-making/STEM/social science } \\
\text { contexts by network; } \\
\text { multimedia circulation of findings } \\
\text { as appropriate; } \\
\text { exploitation of disciplinary and } \\
\text { interdisciplinary reports to produce further } \\
\text { academic outputs, grant applications, etc. }\end{array}$ & $\begin{array}{l}\text { 1. Authoritative, interdisciplinary humanities } \\
\text { report, which brings together and } \\
\text { articulates perspectives from a range of } \\
\text { humanities disciplines on the project topic, } \\
\text { and which can make a valuable } \\
\text { contribution to wider environmental debate } \\
\text { and policy-making. } \\
\text { 2. A platform for further interdisciplinary } \\
\text { collaboration within and beyond the } \\
\text { humanities and academic } \\
\text { outputs/activities. }\end{array}$ \\
\hline
\end{tabular}

\subsection{The Context to the Model: The RSE Network}

The RSE network was established in early 2015 during a time of rapid and significant de-carbonisation in Scotland (Scottish Government 2017, pp. 9-13). The overall objective of the network is to address the issue of what the humanities can bring to the process in order to help mitigate climate change. Since the turn of the century, there has been impressive progress in renewable electricity generation in Scotland, driven largely by the Scottish and UK Governments. The Scottish Parliament's Climate Change (Scotland) Act 2009 (which built on the UK Parliament's Climate Change Act 2008) set the ambitious statutory target of reducing Scotland's carbon emissions by $80 \%$ by 2050: moreover, the 2017 Scottish Government Draft Energy Strategy has proposed an even more challenging target of producing $50 \%$ of Scotland's energy (i.e., electricity and transport and heat) from renewables by 2030 (Scottish Government 2017, p. 10). In this context, renewable electricity generation now accounts for nearly $60 \%$ of Scotland's gross electricity consumption-and much of the rest is now met by the country's two nuclear power stations, which might be thought of as low-carbon (although not renewable) (Scottish Government 2017, pp. 15-21) ${ }^{10}$. While much has been achieved by this technocratic, top-down process in a short period, transition is still, however, in danger of

10 N.b. The statistics presented in the draft strategy date from 2015: since then, the last Scottish coal-fired power station has closed, meaning that the country's electricity generation is now essentially from renewables (mainly on-shore wind turbines and hydro) and its two nuclear power stations (Torness and Hunterston B). 
stalling, and with it further progress on climate change mitigation. Many are broadly in favour of transition, but there is a lack of real public engagement, and the challenge of persuading ordinary people to change their patterns of behaviour when heating their own homes (Scotland is often cold and wet) and travelling for work and pleasure will be much greater than the reforms to the electricity generation sector, which have gone largely unnoticed by consumers. Importantly, addressing heating and transport is vital to achieve a successful low-carbon transition, as electricity accounts for only around $20 \%$ of total Scottish energy consumption, with the remaining $80 \%$ in heat and transport (Scottish Government 2017, ibid.).

Given the significance of cultural narratives in understanding and influencing behaviour, the RSE network seeks to explore the potential for the humanities to help the STEM subjects and policy-makers bridge the public engagement gap. Its overall objective is therefore to identify the cultural influences affecting transition by taking advantage of the potential for broadly moderate, interactional interdisciplinarity involving scholars from across the humanities-from history, literature and theatre, politics, the visual arts, media studies and law-to develop shared understandings of the challenges that Scotland faces. As is expanded on in more detail below, the project's main objective is to create fresh disciplinary perspectives and then to build new inter-humanities understanding: this process can act as a springboard for further interdisciplinary collaboration with STEM subjects, social science and policy makers (Royal Society of Edinburgh Network 2017).

The network builds on the richness of Scottish humanities narratives on energy transitions. Scotland was one of the first and most heavily industrialised and urbanised parts of the UK, and hence the world. It has a powerful sub-national Parliament and Government, a strong and vibrant culture, heritage and identity and its own legal system. Scotland also has significant potential—as indicated above, now realised to a considerable extent-for renewable electricity generation. And, of course, it has a deep history of coal mining, offshore oil and gas extraction and industrial and scientific innovation. As a result, there are many distinctively Scottish environmental stories concerning, among other things, national, local, gender and class identities; the histories and futures of communities; poverty, prosperity and opportunity; peoples' connections with the landscape and wildlife; and the relationships between ordinary citizens, the state and the powerful (Royal Society of Edinburgh Network 2017). In this last context, the energy transition has also provided important narratives in politics and law, including in the ongoing campaigns for and against Scottish independence from the UK. Nuclear energy, fracking, windfarms, the closure of the coalfields and coal fired power stations and the economic importance and recent decline of the North Sea oil and gas industries are all heavily contested politico-legal issues in Scotland (Little 2016b).

\subsection{The Four-Stage Model for Interdisciplinary Collaboration in the Environmental Humanities-Key Points}

\subsubsection{Design}

Making overall sense of the wide range of Scottish narratives is an exciting prospect, but far from straightforward. Indeed, notwithstanding (and in part because of) the embarrassment of socio-cultural riches, it was understood by the RSE network that effective collaboration required careful thought and planning. An important issue that became apparent at the outset was that, notwithstanding differences between the disciplines, there was often limited academic discussion of the narratives. So, key to the design of the model that emerged was the focus on building a solid platform of disciplinary perspectives before developing inter-humanities and then broader interdisciplinary collaboration. Doing so required the disciplines to engage critically with culturally specific Scottish issues and also mitigated against undue emphasis being given to disciplinary positions which may initially have appeared stronger. This approach builds on the SCEHP-based work of Hamilton et al. ((Hamilton et al. 2009, pp. 164-67, 181-85); and see also (Boulton et al. 2005; Benda et al. 2002; Amey and Brown 2005)) in that the primary objective of the first three stages of the model is the structured development of written reports and research questions to provide a knowledge base at 
the disciplinary level. Stage four then engages in a collaborative online process to move scholarship forward across the humanities by producing an inter-humanities report, which in turn provides firm foundations for further interdisciplinary collaboration with the sciences, social sciences and policy-making. The model therefore differs from the approaches taken by projects such as Stories of Change ${ }^{11}$ and Orkney: beside the ocean of time ${ }^{12}$, which use the creation of artworks, stories, poems and other cultural outputs to explore and record interdisciplinary themes on transition and environmental change. It is also distinct from predominantly discipline-centric projects such as Material Cultures of Energy, which was an historical study of how energy transitions transformed daily life in the twentieth century $^{13}$, or Spaces of Experience and Horizons of Experience, which used oral history to explore how people experience climate variation and extreme weather. ${ }^{14}$ And, unlike the Pathways to Understanding Climate Change project ${ }^{15}$, which used ethnographic methods, the focus of the four-stage model is to identify and explore ideas and perspectives within humanities scholarship, rather than on empirical data-collection and social anthropology.

\subsubsection{Stage 1: Network Formation}

The first stage is the creation of a generic cross-disciplinary environmental humanities network comprising scholars interested in a broad theme, such as climate change, environmental pollution, nature conservation, or low-carbon transition. This requires interested and committed individuals to contact colleagues in different humanities disciplines to find out if they are interested in principle in collaboration and interdisciplinary working. As many humanities as possible should be represented, and some may be particularly relevant depending on the theme. The RSE network is a relatively small one, which is focused on the narrow issue of Scottish low-carbon transition. Nonetheless, it was possible to bring together twenty-five specialists in different aspects of literature and theatre, politics, law, media studies, visual arts and history in a short space of time: the network has since grown significantly to involve over eighty people, from throughout the UK and EU. Larger subject areas and projects would, it is reasonable to think, be likely to generate interest from more scholars and disciplines, and collaboration could be scaled up to create partner networks in different countries. While a number of those contacted will, inevitably, not be interested in working as part of a group, the positive experience of the RSE network would suggest that there are many who are-and it is also worth saying that those who were not interested very often made helpful suggestions as to who might be. The main thing that is needed at this stage is for interested individuals to invest time and energy in linking up with suitably qualified people and maintaining connections with them.

At the risk of stating the obvious, it is also necessary to be clear from the start on what the general objective of inter-humanities collaboration actually is. So, in the RSE network, it was recognised that the humanities can provide insights into how issues such as climate change caused by fossil fuel use and transitioning to low-carbon technologies are perceived in Scotland in cultural terms, thereby making a contribution to the effectiveness of policy-making and the STEM subjects in relation to climate change mitigation.

A further point to make is that IT makes this initial organisational phase much more straightforward and speedy to set up than it would otherwise be. As it is difficult to arrange physical meetings, full use can be made of Skype, Dropbox, email and teleconferencing. Face-to-face interaction is, of course, important in order to build working relationships and facilitate open

11 See Stories of Change project website, available at: http:/ / storiesofchange.ac.uk/about (accessed on 30 October 2017).

12 See Orkney: beside the ocean of time project website, available at: http:/ / www.oceanoftime.uk (accessed on 30 October 2017).

3 See the Material Cultures of Energy project website, available at: http:/ / www.bbk.ac.uk/mce/ (accessed on 30 October 2017).

14 See the Spaces of Experience and Horizons of Experience website, available at: http://www.nottingham.ac.uk/research/groups/ weather-extremes / index.aspx (accessed on 30 October 2017).

15 See the Pathways to Understanding Climate Change project website, available at: https://www.cire.group.cam.ac.uk/ PathwaysProject (accessed on 30 October 2017). 
discussion. That said, the experience of the RSE network was that limited resources and the logistical constraints of linking up with more than a handful of people at a time meant that to place too much emphasis on physical meetings could be counter-productive and result in a loss of momentum. There was also the ethical requirement for environmental humanists working on low-carbon transition to minimise their carbon footprint by restricting travel as much as possible. In this context, Skype and teleconferencing-notwithstanding occasional technical glitches and the barriers that they put in the way of establishing personal rapport-were for the most part surprisingly effective, although they did require careful management.

\subsubsection{Stage 2: Project Development}

Once the network has sufficient critical mass, it is possible to move to the second, more subject-specific stage: project development. Typically, the project will be a grant application in an area of interest to network participants. This is when there needs to be free-flowing, horizontal and inclusive dialogue with environmental policymakers and/or science and social science experts, perhaps as part of a steering committee, which focuses on the significance of the research questions and possible outcomes. Otherwise, the project runs the risk of lacking relevance in a wider interdisciplinary context. For example, there would be little point in humanists trying to contribute to policy-making on low-carbon transition without having a good understanding of the scientific, technological and political challenges that are faced by decision-takers in relation to energy generation, supply and security.

There is, of course, a wide range of methods which can be utilised in this context, depending on the nature and size of the project. For example, if the emphasis is on open-textured group discussions of attitudes or broad ideas, use could be made of focus group techniques (Kitzinger 1995; Smithson 2000). In more technical or policy-based areas, it may be appropriate to identify key stakeholders (e.g., government or industry) and to conduct in-depth, semi-structured consultations/interviews, as in the ongoing Royal Society of Edinburgh Energy Inquiry. ${ }^{16}$ An imaginative way of developing collaboration in the context of workshops is to use environmental scenarios-that is, invented 'if/then' stories of the future - to build interaction and understanding between humanities scholars, scientists and policy-makers (Little 2016a, pp. 70-72; Alcamo 2008). There is a number of different scenario techniques which can be adapted (Alcamo and Henrichs 2008, pp. 19-22) and great opportunity for experimentation, but qualitative anticipatory or exploratory scenarios, devised in conjunction with scientists and/or policy-makers, can provide humanities scholars with the situations and themes from which to springboard into cultural analysis.

Larger projects could explore perception-based issues using variations on Delphi method and produce data within and between disciplines/groups using anonymised self-complete surveys with open-ended and closed-ended questions (the latter could use a Likert-type scale) (Adler and Ziglio 1996). This can facilitate less inhibited, measurable participation on a wide range of issues and enable quantitative and qualitative analysis of the data, which could be cross-tabulated across several variables (e.g., discipline, academic rank, experience, gender, etc.). In the RSE project, however, given its relatively small size and resources, it was felt that semi-structured discussion within the network groups conducted according to the Chatham House Rule, combined with the creation of anonymised collective reports produced by an online iterative process, was the most appropriate method of opening up the subject, generating authoritative material and also facilitating personal connections between participants.

Depending on the nature of the project and the availability of funding, it would also be possible to involve participants from a number of different countries, with a view to developing international interdisciplinary research outcomes. Collaboration of this sort has, it is contended, significant potential.

16 See the Royal Society of Edinburgh Energy Inquiry project website, available at: https://www.rse.org.uk/energyinquiry / (accessed on 30 October 2017). 
For example, the model could be used to build cross-border understanding of different cultural perceptions of key issues, such as nature conservation, climate change, pollution, public health or developing urban and rural environments: these perceptions could then be of value to national and international policy-makers.

However, the project is developed, it is vital that all of the interested network participants from across the disciplines are able to contribute fully to the process. If it is felt that the project is dominated or run by a particular discipline or group of disciplines, other potential participants are likely to fall away. There has to be open dialogue and trust between the participants, and the role of project leaders is crucial in engendering this. Colleagues, whatever their discipline or level of academic seniority, should always be comfortable about flying kites and being critical, and disciplinary expertise needs to be respected.

In this context, participants have to have equal time and opportunity to work out their own positions on the key issues and make a full contribution, and the process structured accordingly. This second stage cannot be rushed, although fortunately Dropbox and similar technologies enable dozens of researchers at a time to read through and make iterative changes to working documents online. This can be done anonymously to encourage the free-flow of ideas and arguments, and in the RSE network the panel leads incorporated the participants' input and reported to the network on an anonymised basis. Even a short time ago, this sort of process would have taken much longer to complete, but IT is now able to make a significant difference. A vital task for project leaders in this context is, of course, agreeing timescales and the editing and finalising of documents whilst maintaining and building consensus and open, respectful, non-hierarchical online dialogue.

It is also necessary to have at least one initial plenary meeting which as many people as possible from across the disciplines can attend-either in person or by Skype or teleconference. Again, project leaders have a key role in facilitating discussion and ensuring that there are as few information asymmetries as possible. A meeting of this sort can open up the widest range of project planning issues; identify potential crossed wires; arrive at general questions, aims, milestones and objectives for the disciplines and subsequent interdisciplinary collaboration; and agree in broad terms on working methods. It is useful for a full report of this meeting setting out heads of agreement and next steps to be drafted by project leaders, and circulated online to all participants for anonymous comment: only when there is consensus should the report be adopted by the network and put into operation.

\subsubsection{Stage 3: Disciplinary Panels}

A key feature of the model is the acknowledgment that, in some situations, humanities disciplines may have undeveloped positions, relative both to each other and to the main sciences and social sciences. Time and space is therefore made available for each discipline to consider its own perspectives and to put the contributions that it can make onto a more equal footing before engaging in interdisciplinary activity. It differs in this respect from studies such as the Caring for the future through ancestral time project, in which a team of humanities researchers from different backgrounds worked collectively to explore the importance of awareness of the past in promoting a sustainable future by investigating the motives, practices and values of climate activists who are also members of religious communities. ${ }^{17}$ Similarly, the Royal Society of Edinburgh Energy Inquiry has brought together a group of experts from different disciplines to work together on an interdisciplinary basis from the outset of the project. ${ }^{18}$

The model enables participants to step back into disciplinary panels to evaluate what they can bring to the subject area (see for example Little 2016a, pp. 54-61; Fisher et al. 2009). The RSE network organised itself into disciplinary panels for literature and theatre; media; law; visual art; and history

17 See the Caring for the future through ancestral time project website, available at: http:/ / ancestraltime.org.uk (accessed on 30 October 2017).

18 See RSE Energy Inquiry project website at: https:/ / www.rse.org.uk/energyinquiry/energy-inquiry-committee/ (accessed on 30 October 2017). 
and politics-although other projects could, of course, have different configurations. In terms of the model, each panel is chaired by a lead and is comprised of between five-eight members, drawn from different institutions and of varying levels of academic seniority-larger panels may prove too unwieldy. It was felt important in the RSE network for each panel to include at least one PhD student approaching the end of their period of study: not only are PhD students the academy's future but, given the rapidly evolving nature of the research topic, their contributions are also often cutting-edge. Panels may also contain a number of practitioners rather than academics, as appropriate (e.g., the visual art panel of the RSE network contained practising artists).

How can the panels proceed? Obviously, different projects can adopt different working methods to suit their purposes. In the RSE network, for example, four to six weeks before the panel meeting, each panel member chose two full-length narratives (e.g., a book chapter, or a journal article) that they felt were related or of significance to the theme at issue. Alternatively, a full-length narrative could be replaced with several shorter narratives (e.g., short journal articles, newspaper articles, internet sources) or documentary films, artworks, images, etc., as appropriate. These narratives were then loaded onto the panel Dropbox folder by panel members. Everybody was then able to review all the narratives in the Dropbox folder prior to the meeting, so that they were able to contribute fully to round-table, Chatham House discussion. The model therefore takes advantage of the fact that, despite a wide diversity in terms of subject matter, theory and method, the humanities are able to connect on particular issues by focussing on the analysis of narratives.

At the panel meetings, the chairs and the project PI took minutes of the discussion, which were also audio/video recorded to facilitate the preparation of the panel reports (n.b. the prior permission of all participants was obtained before starting). Again, if participants were unable to attend physically, facilities were available for them to do so via Skype or teleconferencing. Panel members then introduced and spoke to their selected narratives, highlighting the themes and issues that they thought were particularly significant. More broadly, in order to scope and map the topic, panel members were also ready to give their views on semi-structured issues identified at the plenary meeting. So, for example, they were asked to prepare ideas on (1) what they thought the Scottish low-carbon transition narratives in their disciplines were; (2) the dominant themes and issues arising in the narratives; (3) where the narratives are located and the form that they take (e.g., were they predominantly primary sources, were they fictional or factual, or were they found in narratives that are not directly concerned with low-carbon transition); (4) the nature and extent of the relevant academic literature in the disciplines; and (5) whether, to what extent and how it was thought that the narratives affect people's thinking and popular culture in Scotland.

Depending on what seems most effective in light of the selected narratives, and after discussion, the panel chair can structure the session in terms of either a simple sequence of speakers or according to the themes addressed by different narratives. The panel chair then takes stock and summarises the key ideas that emerged.

After the panel meetings, the network PI and panel chair then produce and circulate draft reports of the proceedings for all panel members to review and comment on anonymously as part of an online process. After the review process is closed, the final panel reports are put on Dropbox, and made accessible to all members of the network. An important outcome of the panel process is therefore rapidly produced and authoritative reports on hitherto undeveloped topics, which have been created collectively by teams of experts and which bring together key disciplinary themes and perspectives. In the RSE project, the panels also produced a range of research questions to be taken forward in both disciplinary and interdisciplinary contexts.

With sufficient resources and the effective use of IT, this basic structure and process can be utilised in a range of different subject matters and contexts. Depending on the subject matter and the level of international interest, it would also be possible to build structured and planned collaboration across borders and cultures, thereby facilitating interdisciplinary humanities dialogue internationally, mainly (but not exclusively) through the use of email, Skype, Dropbox and other IT. In the case of low-carbon 
transition, for example, this could involve the creation of networks at national and sub-national levels throughout Europe, each of which would have their own disciplinary panels producing reports on agreed themes. These could enable humanities scholars to collaborate with their counterparts in other European countries and cultures more easily.

\subsubsection{Stage 4: The Inter-Humanities Report}

The final stage in the model moves beyond the disciplinary level and focusses on the creation of an online inter-humanities report, drawing on the different panel reports as its foundation. This is ongoing in the RSE network, following a plenary brainstorming workshop. The network PI, CIs and panel chairs have a crucial role in bringing together the interdisciplinary report. Together, they are responsible for producing an initial draft which synthesises the disciplinary findings set out in the panel reports, highlighting areas where there are confluences and contiguity, and also those areas where there is a lack of consensus or even significant disagreement. The overall objective is to create new blends of perspectives, insights and fresh understanding, which would be beyond any one discipline to have developed independently. The online process creates developed disciplinary and inter-humanities research agendas and questions which can kick-start transformational interdisciplinary dialogue both within the humanities and then with scientists, social scientists and policy-makers.

What makes the method valuable is that it uses inexpensive (indeed often free) IT rather than frequent face-to-face meetings to enable a large group of people-in the case of the RSE project, around ninety participants-to collaborate in the creation of a genuinely interdisciplinary, collective and informed report on largely unexplored issues, and to do so in a relatively short space of time and inexpensively. It differs from the approach taken by larger, well-resourced projects such as the Royal Society of Edinburgh Energy Inquiry, in which the interdisciplinary activity is within a smaller team comprised of single experts drawn from each of the relevant disciplines. ${ }^{19}$

Following the process utilised for the panel reports, but on a larger scale, the draft inter-humanities report is circulated to all members of the network via Dropbox and open to anonymous iterative comment and revision by them: this online process is facilitated and convened by the network PI. Realistically, the number of people involved means that online working using Dropbox is more efficient, significantly cheaper and lower-carbon than multiple face-to-face meetings. At the end of the drafting period, the network PI and CIs are responsible for working up a second draft, to be put onto Dropbox for all network members to give their final comments on. Once a consensus has been reached on the content and findings of the report, it can then be finalised and (subject to the requirements of any funding bodies) made publicly available via the web, along with the disciplinary panel reports. The network can also publicise the outcomes of the collaboration, and distribute multimedia executive summaries for policymakers, colleagues in STEM and social science disciplines, public bodies, schools, the media, industry and NGO stakeholders and the public with a view to contributing to wider environmental debate. In the academic context, the different reports, outputs and experiences can be used to inform the development of further interdisciplinary and discipline-centric networks and connections, research questions and projects, grant applications and academic monographs and journal articles.

It must, of course, be acknowledged that the heavy reliance on IT rather than face-to-face meetings in stage four is potentially problematic in that it may limit discussion and interaction between participants, which may impact on the interdisciplinary dynamic and the content of the final report. Nonetheless, this should be balanced against the model's logistical and environmental benefits, and its relative cost-effectiveness. If funding and time are not constrained, then more face-to-face

19 See RSE Energy Inquiry project website at: https:/ / www.rse.org.uk/energyinquiry/energy-inquiry-committee/ (accessed on 30 October 2017). 
meetings and dialogue could be built into the process. Realistically, however, this will often not be the case, and the model provides a practical way to work around constraints on resources.

If the model was to be broadened out to a large scale, international project, the interdisciplinary reports produced at national levels could facilitate joined-up international collaboration across the humanities. The reports could also provide the platform to create valuable, new connections with STEM subjects and policymakers at local, national and international levels, thereby enabling the humanities to contribute further to the resolution of global environmental problems.

Clearly, collaboration at an international level would require significant resources, as well as national and international academic leadership—it would be challenging. That said, the STEM subjects and policy-making on environmental meta-issues such as mitigating climate change have long been organised and funded at national and international levels: for the humanities to be able to contribute as effectively as possible therefore requires us to be ambitious and proactive, and to continue developing equivalent structures and processes as a matter of urgency.

\subsubsection{Potential Biases}

As with any research method, the model has a number of potential biases which may influence the outcomes. The most obvious ones are as follows. Firstly, there is the potential for bias in the selection of the network members and non-humanities experts, who may in a narrow field be drawn from a small group of specialists (as was the case with the RSE network). This can be mitigated to some extent by seeking to ensure a gender balance, and a mix of participants from a range of different institutions who are at different stages in their careers. Secondly, it is also likely-if not inevitable- that it may not be possible to secure input from some disciplines or from schools of thought within disciplines-for example, no environmental philosophers are taking part in the RSE project. Thirdly, notwithstanding adherence to the Chatham House Rule for discussion and reporting, there is also the potential for the status, reputation or personality of some participants to dominate - the so-called 'halo effect' — which might lead to others feeling inhibited or to a 'group think' mentality. Panel chairs and the network PI and CIs should therefore mitigate against this as sensitively as possible. They can do so by being fair and transparent and by drafting the reports and incorporating written comments on an anonymous basis.

\section{Reflections on the RSE Network Model Experience: Implications for Collaborative Interdisciplinarity and the Environmental Humanities}

While the work of the RSE network is still ongoing, experience of the model thus far has brought five broad issues to the fore, which would be relevant in the event that it is adopted more widely or developed further in other contexts.

Firstly, to return to the importance of involving experts from non-humanities areas in stage 2 project development, it became apparent during different RSE project sessions that the issues that humanities scholars focus on may not always be relevant to those working in policy-making or science and technology. This reiterated the importance of interacting with and engaging in dialogue with colleagues in non-humanities disciplines, particularly at the earliest stages: otherwise, while what emerges may be of interest within the context of individual disciplines or humanities scholarship generally, it may be of limited relevance in wider environmental debate or to decision-takers.

Secondly, there are some striking differences between the different humanities disciplines. Some, such as law, politics or media may be closer to policy and commercial agendas, as they often interact closely with them (Vick 2004, pp. 177-81). This is not always the case, however. For example, the growing interest among law and politics scholars in energy justice as a broad guiding principle in low-carbon transition and climate change mitigation may be relevant to policymakers dealing with issues such as fuel poverty, but it would be considered to be less so in most other areas of environmental/energy policy. Similarly, the focus of politics and legal scholars on theory and the inter-relationships between different levels of governance are relevant to environmental policymakers 
to some extent, but are usually seen as contextual to achieving policy objectives. Visual arts, literature and theatre, are, by comparison with the more technocratic humanities disciplines, sometimes highly politicised or even activist in motivation, while seeming for the most part far removed from the actuality of official policy-making processes: indeed, their focus may, quite reasonably for artistic and academic reasons, be wholly unrelated to it. But being overtly political or activist may cause difficulties for other humanities scholars-and is likely to alienate those in policy-making, the STEM subjects and social sciences.

Coming to terms with this internal complexity of the humanities is, it is argued, a positive and enlightening experience. In the RSE network, it resulted in participants testing the capacity, relevance and significance of their disciplines and of the environmental humanities generally. For many of us, it challenged our established ways of thinking, and shook up ideas of what we think the humanities can do. It often made disciplinary strengths more apparent, as well as areas for development, and provided a greater degree of clarity about their value. And, above all (for me at least), it put it beyond doubt that the lone scholar-or even a single-discipline group-is unlikely to have a major impact, especially on policy.

Thirdly, in the RSE network, all of the disciplinary panels brought together a wide range of different perspectives on the points at issue. Indeed, one of the first things to become apparent in each panel was that there is no such thing as a definitive disciplinary position: while panel members may share the same disciplinary background, they have different individual interests, knowledge bases, approaches and methods. The ability to work in a collegiate and mutually respectful way is therefore essential, all the more so because each of the disciplines often found it very challenging to articulate where they stood in relation to the themes under discussion. As mentioned earlier, it became clear quite quickly to all of the panels that engaging with the issues required some very hard thinking about what individual disciplines are able to contribute, necessitating acknowledgement of sometimes difficult home truths.

For example, the law panel realised that almost without thinking it tended to focus on narratives about electricity generation or oil and gas, perhaps because historically much research activity in the field has tended to concentrate on the activities of legal practitioners working with generating companies, the oil and gas sectors and government policymakers. This focus meant that narratives on crucial climate change mitigation/low-carbon transition issues such as energy efficiency, heating and transport were often missing from or overlooked in the legal literature. Coming to terms with the practice-driven and instrumental nature of law in the environmental context-most of which is statutory or regulatory rather than created by the courts-is also difficult culturally for legal academics, and the panel had to grapple with this as well as thinking about fresh perspectives for environmental law scholarship. The politics panel had to dig deep to work out what the core purpose of politics scholarship in relation to low-carbon transition in Scotland and elsewhere actually is before it could move on to addressing the issues. After much discussion, it felt that the fundamental role of environmental politics scholarship was to analyse political power: who has it, who wants it and how it works. Once this had been clarified, the panel went on to develop ideas on a number of important issues, not least about how interactional and possibly contributory interdisciplinary expertise could be built with the law and media panels. The literature and theatre and visual arts panels, while able to analyse themes and issues emerging from different forms of low-carbon narratives, often found it difficult to articulate the capacity of their disciplines to connect with policy-making and governance, which are fundamental to the delivery of effective low-carbon transition at the societal level. In this context, the visual arts panel ultimately took the view that art cannot change peoples' behaviour in relation to low-carbon transition in a direct way (as politics or law can). What it can do, however, is have a potentially powerful influence on how individual people-including policy-makers-come to perceive environmental challenges. But for this to happen would effectively require a re-appraisal of the relationships between artists and their practice, and those who support, buy and curate their work. 
After having gone through this process of frank self-reflection, however, each of the panels was able to develop themes and research questions to be taken forward in the development of an overarching inter-humanities report. It enabled participants to build a clearer picture of what the different humanities disciplines can usefully do, and how future collaboration between them can be structured in order to maximise potential and interact with other disciplines.

Fourthly, it was apparent in the RSE network that—understandably—many humanities scholars have very limited knowledge of science/social science quantitative methods and modelling. Of course, some humanities disciplines use both quantitative and qualitative methods, just as much social science is predominantly qualitative, as opposed to quantitative. Nonetheless, it is fair to say that contributory collaboration with quantitatively-focused scientists and social scientists-as opposed to interactional collaboration with them at stage 2 of the model (i.e., project development)—would often be so-called radical interdisciplinarity. As such, it would involve bridging large disciplinary gaps.

By contrast, the RSE network suggests that interaction between humanities scholars (and with qualitative social scientists) is easier to develop (see also (Little 2016a, p. 64; DEA 2008)). Despite methodological and substantive differences, there is often significant intellectual contiguity between disciplines such as, for example, history, law and politics; literature and performing arts; or visual arts and media. Collaboration between colleagues in environmental humanities can therefore often lead to interactional interdisciplinarity, and it has a reasonable prospect of developing beyond that into contributory expertise. Everybody involved is concerned with different aspects of similar socio-cultural issues, such as how to better understand and improve society's responses to pollution, climate change, or the social process of transition to a low-carbon future.

That said, the RSE network also suggests that this potential should not be exaggerated: there is still a wide spectrum of connectivity within the humanities. So, for example, while history, politics and legal scholars might often find that they are concerned with closely related issues, the degree of connection between, say, an environmental lawyer and a visual artist would be more radical. Nonetheless, it would most likely still be moderate by comparison with the connection between a literature scholar and a climate scientist specialising in advanced quantitative modelling. In simple terms, therefore, working collaboratively within the humanities, although often difficult, is a much more realistic prospect than attempting to develop radical contributory expertise. Indeed, and although there have been a number of successful collaborations between the sciences, social sciences and the humanities (in the UK, the Royal Commission on the Environment is perhaps still the exemplar (Royal Commission 1998)), the difficulties involved in trying to establish contributory expertise between most humanities disciplines and quantitatively-focussed scientific disciplines in particular are such that it should not be embarked on without extensive planning and resourcing.

A fifth point which emerged in the course of the RSE network is the importance of mapping where humanities disciplines lie relative to each other on the radical/moderate interdisciplinary spectrum. If there is better understanding of where and how disciplines are most likely to be able to make valuable contributions to interdisciplinary contributions on environmental issues, then this not only benefits the disciplines themselves, but also maximises the potential for effective planning of, and engagement in, interdisciplinary projects. Thus, in the RSE network, it has become apparent that disciplines such as politics, law and media can work together to make powerful contributions to understanding the significance and power of different types of official narratives at collective and societal levels. They really struggle, however, to connect their narratives and analyses with personal experience and motivations, which is also very important when, as is the case with low-carbon transition, influencing individual behaviour is a key issue. Literature, theatre, media and history are often able to do both in different ways and contexts, and while discourse in the visual arts can sometimes seem to get "stuck" on the practice of individual artists, leading eco-artists such as Helen and Newton Harrison have demonstrated that art can have significant influence on society through dynamic engagement with policy-makers (Harrison and Harrison 2016). Thinking through and systematising this sort 
of interdisciplinary dynamic is, it is contended, valuable in developing the overall impact of the humanities in wider environmental debate: it is also rewarding as an interdisciplinary exercise in itself.

\section{Conclusions}

There is a developing consensus that the environmental humanities have much to offer the STEM subjects and social sciences, and policy-makers. There is, however, much less agreement about the best ways to do so effectively. Without being prescriptive, this article stresses the importance of developing collaborative, team-based interdisciplinarity, in addition to traditional solo scholarship.

With this in mind, the article focuses on outlining and reflecting on a four-stage model, based on ongoing experience of the environmental humanities in action in the Royal Society of Edinburgh Research Network in the Arts and Humanities, Connecting with a low-carbon Scotland. The model can be adapted to suit a variety of different themes, projects and scales of operation, but is most appropriate for use in areas where humanities scholarship is still relatively undeveloped. Through disciplinary panels and the use of IT, it enables the rapid and structured production of discipline-level reports, which provide a level playing field for the creation of an inter-humanities report: this can, in turn, serve as a firm foundation for wider interdisciplinary collaboration with the sciences, social sciences and policy-making. While it is labour-intensive, the model thereby seeks to facilitate the strengthening of individual disciplines and the development of interdisciplinary collaboration within and beyond the humanities. It takes advantage of the intellectual contiguity which exists in the humanities and uses it as a 'force multiplier' to produce outputs on a scale, and with a scope and speed, which is exponentially greater than those of lone scholars or collaborations within single disciplines. By working together in this and other ways, the humanities can, it is believed, have a major impact on wider debate and solving global environmental problems.

Acknowledgments: The Royal Society of Edinburgh funded the Connecting with a Low-carbon Scotland Research Network in the Arts and Humanities, which is acknowledged gratefully.

Conflicts of Interest: The author declares no conflict of interest.

\section{References}

Adamson, Joni, and Michael Barry Davis, eds. 2017. Humanities for the Environment: Integrating Knowledge, Forging New Constellations of Practice. Abingdon: Routledge, ISBN 1317283651, 9781317283652.

Adler, Michael, and Erio Ziglio, eds. 1996. Gazing into the Oracle: The Delphi Method and Its Application to Social Policy and Public Health. London: Jessica Kingsley, ISBN 1853021040.

Alcamo, Joseph, ed. 2008. Environmental Futures: The Practice of Environmental Scenario Analysis. Amsterdam: Elsevier, ISBN 9780444532930.

Alcamo, Joseph, and Thomas Henrichs. 2008. Towards Guidelines for Environmental Scenario Analysis. In Environmental Futures: The Practice of Environmental Scenario Analysis. Edited by Alcamo Joseph. Amsterdam: Elsevier, pp. 13-36, ISBN 9780444532930.

Amey, Marilyn J., and Dennis F. Brown. 2005. Interdisciplinary collaboration and academic work: A case study of a university-community partnership. New Directions for Teaching and Learning 102: 23-35. [CrossRef]

Benda, Lee E., Leroy Poff, Christina Tague, Margaret Palmer, James Pizzuto, Scott Cooper, Emily Stanley, and Glenn Moglen. 2002. How to avoid train wrecks when using science in environmental problem solving. BioScience 52: 1127-36. [CrossRef]

Boulton, Andrew J., Debra Panizzon, and Julian Prior. 2005. Explicit knowledge structures as a tool for overcoming obstacles to interdisciplinary research. Conservation Biology 19: 2026-29. [CrossRef]

Bruce, Ann, Catherine Lyall, Joyce Tait, and Robin Williams. 2004. Interdisciplinary integration in Europe: The case of the Fifth Framework Programme. Futures 36: 457-70. [CrossRef]

Chakrabarty, Dipesh. 2009. The Climate of History: Four Theses. Critical Inquiry 35: 197-222. [CrossRef]

Clapp, Brian W. 1994. An Environmental History of Britain Since the Industrial Revolution. London: Longman, ISBN 0582226260. 
Collins, Harry, and Robert Evans. 2002. The Third Wave of Science Studies: Studies of Expertise and Experience. Social Studies of Science 32: 235-96. [CrossRef]

Collins, Harry, and Robert Evans. 2015. Expertise Revisited, Part I-Interactional Expertise. Studies in History and Philosophy of Science 54: 113-23. [CrossRef] [PubMed]

Cover, Robert M. 1983. Foreword: Nomos and Narrative. Harvard Law Review 97: 4-68.

DEA. 2008. Thinking Across Disciplines-Interdisciplinarity in Research and Education. Copenhagen: Danmarks Erhvervsforskningsakademi, Available online: http://www.dea.nu/sites/default/files/Thinking\% 20Across\%20Disciplines\%20-\%20Interdisciplinarity\%20in\%20Research\%20and\%20Education_0.pdf (accessed on 14 November 2017).

Derry, Sharon J., Christian D. Schunn, and Morton Ann Gernsbacher, eds. 2013. Interdisciplinary Collaboration: An Emerging Cognitive Science. New York: Psychology Press, ISBN 0-8058-3633-0.

Dryzek, John S. 2005. The Politics of the Earth, 2nd ed. Oxford: Oxford University Press, ISBN 978-0199277391.

Eckersley, Robyn. 1992. Environmentalism and Political Theory: Toward an Ecocentric Approach. London: UCL Press, ISBN 1857280202.

EURAB (EU Research Advisory Board). 2004. Interdisciplinarity in Research. Available online: https: / / ec.europa.eu/research/eurab/pdf/eurab_04_009_interdisciplinarity_research_final.pdf (accessed on 14 November 2017).

European Science Foundation and European Cooperation in Science and Technology. 2012. Responses to Environmental and Societal Challenges for Our Unstable Earth (RESCUE). Strasbourg: European Science Foundation, Brussels: European Cooperation in Science and Technology, ISBN 978-2-918428-56-5. 60p. Available online: http://archives.esf.org/fileadmin/Public_documents/Publications/rescue.pdf (accessed on 14 November 2017).

Fisher, Elizabeth. 2016. Expertise-A Short Contribution to the SLS Environmental Law Section Panel Discussion on 'Interdisciplinary Environmental Law Scholarship in Practice: Space, Audience, and Expertise'. Unpublished manuscript, dated 22 August 2016.

Fisher, Elizabeth, Bettina Lange, Eloise Scotford, and Cinnamon Carlarne. 2009. Maturity and Methodology: Starting a Debate about Environmental Law Scholarship. Journal of Environmental Law 21: 213-50. [CrossRef]

Fisher, Elizabeth, Bettina Lange, and Eloise Scotford. 2013. Environmental Law: Text, Cases and Materials. Oxford: OUP, ISBN 987-0-19-927088-0.

Frost, Susan H., and Paul M. Jean. 2003. Bridging the disciplines: Interdisciplinary discourse and faculty scholarship. Journal of Higher Education 74: 119-49. [CrossRef]

Fuller, Lon L. 1978. The Forms and Limits of Adjudication. Harvard Law Review 92: 353-409. [CrossRef]

Funtowicz, Silvio, and Jerome R. Ravetz. 1991. A new scientific methodology for global environmental issues. In Ecological Economics: The Science and Management of Sustainablity. Edited by Robert Costanza. New York: Columbia University Press, pp. 137-52. ISBN 0-231-07563-4.

Gabrielson, Teena, Cheryl Hall, John M. Meyer, and David Schlosberg, eds. 2016. The Oxford Handbook of Environmental Political Theory. Oxford: OUP, ISBN 9780199685271.

Gardiner, Stephen M., and Allen Thompson, eds. 2015. The Oxford Handbook of Environmental Ethics. Oxford: OUP.

Garrard, Greg, ed. 2014. The Oxford Handbook of Ecocriticism. Oxford: Oxford University Press, ISBN 9780199742929.

Griffiths, Tom. 2007. The humanities and an environmentally sustainable Australia. Australian Humanities Review. Available online: http://www.australianhumanitiesreview.org/archive/Issue-December-2007/ EcoHumanities / EcoGriffiths.html (accessed on 14 November 2017).

Hamilton, Alistair, Fiona Watson, Althea Davis, and Nick Hanley. 2009. Interdisciplinary Conversations: The Collective Model. In Nature's End: History and the Environment. Edited by Sverker Sörlin and Paul Warde. Basingstoke: Palgrave Macmillan, pp. 162-87. ISBN 978-0-230-20346-4.

Harrison, Helen Mayer, and Newton Harrison. 2016. The Time of the Force Majeure: After 45 Years Counterforce Is on the Horizon. Munich: Prestel, ISBN 379135549X.

Heise, Ursula K. 2014. Comparative Ecocriticism in the Anthropocene. In Komparatistik. Heidelberg: Synchron, pp. 19-30, ISSN 1432-5306.

Heise, Ursula K. 2017. Introduction: Planet, species, justice-And the stories. In The Routledge Companion to the Environmental Humanities. Edited by Ursula K. Heise, Jon Christensen and Michelle Norman. Abingdon and New York: Routledge, pp. 1-10, ISBN 97811387886745. 
Heise, Ursula K., Jon Christensen, and Michelle Norman, eds. 2017. The Routledge Companion to the Environmental Humanities. Abingdon and New York: Routledge, ISBN 97811387886745.

Holm, Poul, Michael Evan Goodsite, Sierd Cloetingh, Mauro Agnoletti, Bedrich Moldan, Daniel J. Lang, Rik Leemans, Joergen Oerstroem Moeller, Mercedes Pardo Buendía, Walter Pohl, and et al. 2013. Collaboration between the natural, social and human sciences in Global Change Research. Environmental Science \& Policy 28: 25-35. [CrossRef]

Holm, Poul, Joni Adamson, Hsinya Huang, Lars Kirdan, Sally Kitch, Iain McCalman, James Ogude, Marisa Ronan, Dominic Scott, Kirill Ole Thompson, and et al. 2015. Humanities for the Environment-A Manifesto for Research and Action. Humanities 4: 977-92. [CrossRef]

Isenberg, Andrew C., ed. 2014. The Oxford Handbook of Environmental History. Oxford: OUP, ISBN 9780195324907. Jamieson, Dale. 2017. The Anthopocene: Love it or leave it. In The Routledge Companion to the Environmental Humanities. Edited by Ursula K. Heise, Jon Christensen and Michelle Norman. Abingdon and New York: Routledge, pp. 13-20, ISBN 97811387886745.

Kitzinger, Jenny. 1995. Qualitative Research: Introducing focus groups. British Medical Journal 311: 299. [CrossRef] [PubMed]

Klein, Julie Thompson. 1996. Crossing Boundaries: Knowledge, Disciplinarities and Interdiciplinarities. Charlottesville: University Press of Virginia, ISBN 0813916798.

Klein, Julie Thompson. 2008. Evaluation of Interdisciplinary and Transdisciplinary Research. American Journal of Preventative Medicine 35: S116-S123. [CrossRef] [PubMed]

Latour, Bruno. 1991. We Have Never Been Modern. Translated by Porter Catherine. 1993; Cambridge: Harvard University Press, ISBN 0674948394.

Little, Gavin. 2016a. Developing environmental law scholarship: Going beyond the legal space. Legal Studies 36: 48-74. [CrossRef]

Little, Gavin. 2016b. Energy and the Scotland Act 2016. Edinburgh Law Review 20: 394-99. [CrossRef]

Martell, Luke. 1994. Ecology and Society: An Introduction. Cambridge: Polity Press, ISBN 9780745610238.

McNeill, John R. 2001. Something New Under the Sun. New York: W.W. Norton, ISBN 978-0-393-32183-8.

National Academy of Sciences, the National Academy of Engineering, and the Institute of Medicine. 2005. Facilitating Interdisciplinary Research. Washington: National Academies Press. [CrossRef]

Padmanabhan, Martina. 2017. Transdisciplinarity for Sustainability. In Transdisciplinary Research for Sustainability. Edited by Martina Padmanabhan. London: Routledge, ISBN 101138216402.

Palsson, Gisli, Bronislaw Szerszynski, Sverker Sörlin, John Marks, Bernard Avril, Carole Crumley, Heide Hackmann, Poul Holm, John Ingram, Alan Kirman, and et al. 2013. Reconceptualizing the 'Anthropos' in the Anthropocene: Integrating the social sciences and humanities in global environmental change research. Environmental Science Policy 28: 3-13. [CrossRef]

Pennington, Deana D. 2008. Cross-disciplinary collaboration and learning. Ecology and Society 13: 8. Available online: http:/ / www.ecologyandsociety.org/vol13/iss2/art8/ (accessed on 14 November 2017). [CrossRef]

Plumwood, Val. 2001. Environmental Culture: The Ecological Crisis of Reason. London: Routledge, ISBN 0415178789.

Polk, M. 2014. Achieving the promise of transdisciplinarity: A critical exploration of the relationship between transdisciplinary research and societal problem solving. Sustainablility Science 9: 439-51. [CrossRef]

Roberts, Neil. 2014. The Holocene. An Environmental History, 3rd ed. Oxford: Wiley-Blackstone, ISBN 978-1-4051-5521-2.

Rogers, Yvonne, Mike Scaife, and Antonio Rizzo. 2013. Interdisciplinarity: An Emergent or Engineered Process? In Interdisciplinary Collaboration: An Emerging Cognitive Science. Edited by Sharon J. Derry, Christian D. Schunn and Morton Ann Gernsbacher. New York: Psychology Press, ISBN 0-8058-3633-0.

Rose, Deborah B., Thom van Dooren, Matthew Chrulew, Stuart Cooke, Matthew Kearnes, and Emily O'Gorman. 2012. Thinking Through the Environment, Unsettling the Humanities. Environmental Humanities 1: 1-5. Available online: http://environmentalhumanities.org/arch/vol1/EH1.1.pdf (accessed on 14 November 2017). [CrossRef]

Royal Commission (Royal Commission on Environmental Pollution). 1998. Twenty-First Report: Setting Environmental Standards; Cm 4053; London: Royal Commission on Environmental Pollution. 
Royal Society of Edinburgh Network. 2017. Research Network in the Arts and Humanities Connecting with a Low-Carbon Scotland. Available online: https://www.stir.ac.uk/cehp/projects/connectingwithalowcarbonscotland/ (accessed on 30 October 2017).

Scottish Government. 2017. Scottish Energy Strategy: The Future of Energy in Scotland; Edinburgh: Scottish Government. Available online: http:/ / www.gov.scot/Resource/0051/00513466.pdf (accessed on 14 November 2017).

Shaw, Jan. 2013. Story streams: Stories and their tellers. In Storytelling: Critical and Creative Approaches. Edited by Jan Shaw, Philippa Kelly and Liam E. Semler. Basingstoke: Palgrave Macmillan, pp. 1-15. ISBN 1137349948.

Sheail, John. 2002. An Environmental History of Twentieth Century Britain. Basingstoke: Palgrave Macmillan, ISBN 0333949811.

Simmonds, Ian G. 2001. An Environmental History of Great Britain from 10,000 Years Ago to the Present. Edinburgh: Edinburgh University Press, ISBN 0748612831.

Smithson, Janet. 2000. Using and analysing focus groups: Limitations and possibilities. International Journal of Social Research Methodology 3: 103-19. [CrossRef]

Smout, Thomas Christopher. 2009. Exploring Environmental History: Selected Essays. Edinburgh: Edinburgh University Press, ISBN 0748635130.

Sörlin, Sverker. 2012. Environmental humanities: Why should biologists interested in the environment take humanities seriously? BioScience 62: 788-89. [CrossRef]

Sörlin, Sverker. 2013. Reconfiguring environmental expertise. Environmental Science and Policy 28: 14-24. [CrossRef]

Sörlin, Sverker, and Paul Warde, eds. 2009. Nature's End: History and the Environment. Basingstoke: Palgrave Macamillan, ISBN 0230203469, 9780230203464.

Steffen, Will, Jaques Grinevald, Paul Crutzen, and John McNeill. 2011. The Anthropocene: Conceptual and historical perspectives. Philosophical Transactions of the Royal Society A 369: 842-67. [CrossRef] [PubMed]

Stern, Lord Nicholas. 2016. Building on Success and Learning from Experience: An Independent Review of the Research Excellence Framework; London: Department for Business, Energy \& Industrial Strategy. Available online: https:/ / www.gov.uk/government/publications/research-excellence-framework-review (accessed on 14 November 2017).

Turner, Monica G., and Stephen R. Carpenter. 1991. Tips and traps in interdisciplinary research. Ecosystems 2: 275-76. [CrossRef]

Vick, Douglas W. 2004. Interdisciplinarity and the discipline of law. Journal of Law and Society 31: 163-93. [CrossRef] Warde, Paul. 2008. Energy Consumption in England and Wales 1500-2000. Naples: Consiglio Nazionale della Ricerche, ISBN 978-88-8080-082-8.

(C) 2017 by the author. Licensee MDPI, Basel, Switzerland. This article is an open access article distributed under the terms and conditions of the Creative Commons Attribution (CC BY) license (http:/ / creativecommons.org/licenses/by/4.0/). 